Continuous Consistent Voting

\title{
Continuous Consistent Voting: Individual- and Institutional-Level Predictors of Preference-Consistent Voting in 48 Democracies
}

\author{
Young, D. J. and de-Wit, L. H. (2021). \\ Department of Psychology, University of Cambridge
}

\begin{abstract}
Scholars have debated whether democracy suits human nature for millennia. Since democracies and people are diverse, some people may be better suited to democracy, and some democratic systems more suited to humanity. This study investigates whether and in what ways this is true. We conceptually replicate and extend Lau et al. (2013) by measuring how closely citizen's Head-of-State vote choices match their political preferences using data from the Comparative Study of Electoral Systems, investigating 147 elections from 48 countries between 1996-2018 ( $N=260,282)$. We explore individual- and institutional-level predictors using a continuous measure of multi-dimensional preference-consistent voting, something hitherto missing from the literature. Efficacy, political sophistication, and age all increase consistency; systems with clear lines of responsibility increase but personal vote incentives decrease consistency. Proportional systems do not increase consistency overall, but in countries with both single-member- and multi-member-district electoral tiers, votes are more consistent in (more-proportional) multi-member tiers.
\end{abstract}

Keywords: democracy, political decision-making, heuristics, Correct Voting, proportionality 
Continuous Consistent Voting

Scholars have questioned whether human nature is suited to democracy since antiquity. From Plato's "ship of fools" analogy to Mill's warnings of the "tyranny of the majority", many have concluded that it is not. But democracies and humans come in different forms, which prompts the question: are certain electoral systems better suited to human psychology than others, and are there are individual-level traits that are predictive of better democratic decision making? Defining good political decision making is a deeply challenging ethical issue. This work builds on previous attempts to quantify this by looking at one definition of good political decision making based on a form of preference aligned voting called "correct voting". Building on previous work by Lau et al. (2013) this study develops a new continuous measure of "correct voting”, which we term 'Continuous Consistency'. This work explores both individual and institutional-level predictors of Continuous Consistency across all five published waves of the Comparative Study of Electoral Systems (“CSES”).

\section{Standards of Electoral Decision-Making}

Trust in democracy has been in decline over the last 25 years (Foa, Klassen, Slade, Rand, \& Collins, 2020), and there are increasing concerns over the biases that people bring to democratic decision making (e.g. Jost, Glaser, Kruglanski, \& Sulloway, 2003; Todorov, Mandisodza, Goren, \& Hall, 2005), and the robustness of different institutions. One approach to understanding the extent to which individual traits and institutional factors are important to the health of a democracy is to employ empirical standards for the quality of electoral decision making. These standards all have limitations, but they offer an opportunity to empirically compare voting decisions across individuals and institutional contexts. One important class of empirical standards are preference-based standards. These standards contend that citizens vote well when they vote in accordance with their own preferences. These standards 


\section{Continuous Consistent Voting}

have an intuitive appeal because the function of elections is to select representatives who will discharge the preferences of the people through government - as Dalton (2015) asserts, "A strong linkage between the political views of the public and political

elites is one of the essential features of democratic political systems" (p.1). If voters fail to adequately express their preferences through their vote, they will fail to achieve adequate representation.

One prominent preference-aligned standard is the "correct vote" standard. This definition was originally introduced with the idea that a citizen is said to vote "correctly" when "under conditions of incomplete information [they] nonetheless actually choose the candidate they would have chosen had they been fully informed about the issues and candidates running in that election" (Lau, Patel, Fahmy, \& Kaufman, 201, p.240). In this conception, the main obstacles voters face to voting in accordance with their preferences are information deficits which inhibit their ability to recognise which parties most fulfil those preferences. The correct voting approach does not assume that a lack of information will necessarily cause voters to make poor electoral decisions, as voters can deploy heuristics to compensate for deficits, but suggests that whether they do is an empirical question.

A number of methodological approaches to measuring levels of correct voting have been implemented. Most commonly, researchers to devise an algorithm which can determine the party for whom an individual should vote on the basis of a full consideration of their preferences and the characteristics of the parties, then compare these prescriptions to actual voting records, typically using survey data. The determination of the "correct" party is based upon calculating utility scores for each voter-party dyad. It is assumed that voters would vote for the utility-maximising party under full information, therefore voters who do vote for that party are "correct" voters, 
Continuous Consistent Voting

and those who don't "incorrect". Having identified which citizens vote "correctly", researchers can then explore the predictive factors of correct voting.

In the original correct voting study (Lau \& Redlawsk, 1997), three factors were used to calculate utility scores. The first, favourability of issue stands, was calculated by comparing participants' and parties' positions along a number of policy dimensions using Rabinowitz and MacDonald (1989)'s measure of directional difference, which assumes that voters prefer positions on 'their side' of the ideological spectrum rather than positions proximal to their own per se. The second factor, group endorsements, was calculated by measuring to what extent the participant and candidate agreed about which social groups they viewed favourably. The third factor, favourability of personality descriptions, was calculated by measuring to what extent the candidate fulfilled the participant's preferences for a candidate's personal attributes. Each factor was weighted by the candidate's assessment of its importance to their own previous vote choices, then summed to produce a utility score. Lau and Redlawsk (1997) applied this algorithm to Presidential election data from the American National Election Survey $1972-1988$, finding a mean correct voting frequency of $75 \%$. This suggests that citizens' electoral decision-making heuristics are sufficiently effective that insufficient information only causes 1 in 4 voters to vote for a party other than the one they would vote for if they had full information.

Lau and Redlawsk (1997)'s correct voting algorithm was validated against data from an experiment in which participants voted twice in an artificial election, once under partial information, then again under full information, allowing them to observe the information upon which voters rely to make "correct" decisions. However, most subsequent studies adapt validated algorithms from previous studies, or simply use literature to determine how preferences and information can be combined to predict 
Continuous Consistent Voting

vote choice. For example, Lau et al. (2013) identified three factors of vote choice from literature - whether a citizen feels close to a party, their evaluation of that party's prior performance, and the directional difference between their and the party's ideological position.

The concept of correct voting is open to numerous objections. For one, it assumes all failures to vote "correctly" are due to a lack of information. In reality, citizens may deviate from their assigned "correct" vote simply by combining their preferences in a different fashion to that determined by the algorithm. The terminology of "correct voting" has also been criticised for the pejorative connotations it associates with "incorrect" voters. As Baldassarri (2013) argues, researchers are in no position to designate particular voters as having made "incorrect" decisions, as voters are free to set their own criteria for whom to vote. This lends the terms "incorrect" and "correct" narrow meanings which are removed from their intuitive interpretations, and so some researchers have adopted different terminology. Baum and Jamison (2006) for instance adopt the term "consistent" rather than "correct". In this paper, we follow this example, and use the intuitively neutral terminology of "consistent" voting when discussing our design and results.

The correct vote standard is not the only standard of vote 'quality'. Another standard is policy-alignment, which is subtly different for its focus only on issues of policy or ideology. Both standards can be thought of as 'preference-aligned' standards, since they presume that to vote well is to vote in alignment with one's preferences, but they focus on different dimensions of political preference. In the policy-alignment literature, there exist many ways of measuring the extent to which citizens vote for parties whose policy positions most closely match the voter's own. Some researchers measure the distance between voter-party dyads along specific 
policy dimensions like favourability towards EU integration (e.g. Dalton, 2015), or broader ideological dimensions (Boonen, Pedersen, \& Hooghe, 2017). Others adapt the correct voting approach to consider only policy and ideology factors (e.g. Singh, 2010). The correct voting and policy-aligned voting standards inform us about different aspects of the 'quality' of electoral decision-making. The correct vote standard is useful for its breadth, as it incorporates multiple preference domains, including candidate evaluations and how 'close' citizens feel to parties. Another challenge with a policy focused measure of alignment is that it is difficult to analyse cross-nationally since the important policy issues across different countries are frequently not comparable, and in any case the required data - information about both where citizens and parties stand on a common pool of policy issues, across multiple countries - often does not exist. The empirical work presented in this paper therefore explores only the correct voting standard. Though not an exhaustive or unique standard of democratic voting quality, it provides us with a means to quantitatively analyse some important properties of voting behaviour.

Whilst the measure of consistent voting adopted here is advantageous in focusing on three measures that can be compared across many countries, there is an important caveat to this comparison. This measure only provides a relative measure of preference aligned voting within each country - it does not enable an absolute comparison across countries. This is because within each country correct votes are defined as those where the participant's choice matches the best party available to them. Across countries however, the optimality of this match could differ in absolute terms, for example the best match for a voter in the UK could be less optimal than the best match for a voter with the same preferences in the Netherlands. This measure 
Continuous Consistent Voting

should therefore be understood as reflecting the degree of error voters make given the choices that are available to them.

Given the current academic focus on the potential 'irrationality' of voters (e.g. van Bavel \& Pereira, 2018), and indeed the growing literature within psychology and behavioural economics on the ways in which humans are not just error prone, but make systematic and predictable errors (Kahneman, 2011), this operationalisation of correct voting is still particularly important, as it puts the emphasis upon whether voters make optimal decisions given the choices available to them. It is clear that voters face serious difficulties obtaining and integrating information about politics (Downs, 1957; Simon, 1985, 1995), and as a result often display low levels of political knowledge (Delli Carpini \& Keeter, 1996) and ideological consistency (Converse 1964, though see Jost 2006). Correspondingly, scholars have suggested voters might still be able to make good decisions by using heuristics for both efficiently gathering information (Popkin, 1991; Sniderman, Brody, \& Tetlock, 1991; Lau, Andersen, \& Redlawsk, 2008; Conover \& Feldman, 1989; Lodge \& Taber, 2000) and combining it into summary judgments (Baldassarri, 2012). Heuristics are simple rules-of-thumb that often, but not always, provide solutions for difficult-to-solve cognitive problems.

Heuristics work best when they exploit salient features of the environment that serve as cues to the correct solution (Todd \& Gigerenzer, 2000). Political decision-making environments bear this feature as party's policy proposals are typically "bipolar and coordinated across issues" (p.218, Jackman \& Sniderman, 2002), meaning voters can use agreement with a party on a small number of issues to infer that they likely agree with them more broadly. Indeed, Goren (2013) suggests voters use a 'policy principles heuristic', choosing a few salient and divisive policy issues with which to efficiently differentiate parties who share their preferences from 
those who don't. There is empirical evidence voters use a variety of heuristics (Baldassarri, 2012; Lau, Kleinberg, \& Ditonto, 2018; Steenbergen \& Colombo, 2018), though not necessarily optimally (Kuklinski \& Quirk, 2000). Moreover, some heuristics are suited better to some electoral systems than others (Lau et al., 2013). Altogether this literature establishes that we cannot judge the quality of voters' decisions from theory alone, as much will depend upon which heuristics voters use and how they deploy them in a given electoral context. Rather, it is necessary to empirically measure the quality of citizens' electoral voting decisions, considering both individual- and institutional-level effects. We now review existing literature on factors affecting citizens' voting decisions.

\section{Predictors of Preference-Aligned Voting}

Predictors of electoral decision-making quality can be characterised as features of individuals or of institutions, with 'institutions' referring to a nation's "laws, the party system that developed in response to those laws, and its incumbent government" (Lau et al. 2013, p.245). In Lau et al.'s (2013) conception, individual factors determine citizens' ability to make good electoral decisions, while institutional factors affect the difficulty of those decisions, and voters' motivation to engage in effortful decisionmaking processes. Electoral institutions can also affect decision difficulty by altering the information voters require and how easily they can acquire it. Further, they can affect citizens' voting behaviour by instantiating particular incentive structures.

\section{Individual-level predictors}

Knowledge and Sophistication. Measures related to citizens' knowledge and cognitive ability are routinely investigated as predictors of voting quality. Some studies directly measure citizens' political knowledge by asking them questions about contemporary national politics (Lau et al., 2013), others combine knowledge scores of 


\section{Continuous Consistent Voting}

this kind with education level in an additive scale of 'political sophistication' (Lau et al., 2008), whereas others infer sophistication from an individual's education level (Singh, 2010). Sophistication and knowledge, though distinct constructs, are essentially used interchangeably and invariably produce concordant findings (Rapeli, 2018).

Knowledgeable citizens typically achieve higher preference-alignment - Rapeli (2018) describes the evidence as such as "overwhelming". For example, Lau et al. (2013), in a comparative study of 69 elections across 33 countries, find citizens with higher levels of 'political sophistication' are more likely to vote "correctly" and Singh (2010) finds that higher-educated citizens are more likely to vote for the party whose ideological position is closest to their own in a cross-national comparative study. Additionally, knowledge can enhance the effectiveness with which heuristics are deployed (Sniderman et al., 1991).

However, some studies find null effects of knowledge on vote quality. For instance, both Simas (2013) and Joesten and Stone (2014) find no relationship between political knowledge and voter-party ideological proximity in US House of Representatives elections, and Sokhey and McClurg (2012) find no effects of knowledge on levels of correct voting using the 1992 Canadian National Election Survey and the 2000 American National Election Survey. One factor which complicates comparison between studies, aside from the heterogeneous measures of vote quality and operationalisation of the knowledge variables, is that different researchers invariably include different sets of covariates in their regression models. For instance, Simas (2013) include the affiliation of the incumbent and ethnicity of the voter, and Sokhey and McClurg (2012) include characteristics of voters' social networks, as do Joesten and Stone (2014), who also include dummy variables for the use of several heuristics. Theoretically, any covariate which itself is a source of 
Continuous Consistent Voting

political information, or which can compensate for the detrimental effects of low information, might render a political knowledge variable insignificant. Indeed, Sokhey and McClurg (2012) and Joesten and Stone (2014) explicitly suggest that social networks propagate political information to citizens, and include related variables as covariates. Thus although knowledge appears to affect levels of preference-aligned voting, whether this relationship is significant once the effects of heuristics and other sources of information has been properly accounted for remains unclear.

Political Efficacy. Political efficacy defined by Campbell, Gurin, and Miller (1954) as the "feeling that political and social change is possible and that the individual citizen can play a part in bringing about this change" (p.187), is thought to enhance citizens' motivation to invest effort in political decision-making. Lau et al. (2013) argue that "people who believe they have the influence to influence their political outcomes should generally be more strongly motivated to put in the effort to try to vote correctly" (p.244), and indeed find that efficacy is predictive of correct voting.

Age. The effects of age upon preference-alignment are mixed. Analyses of artificial election experiments find that voters become worse at integrating information about electoral alternatives as they age (Lau and Redlawsk, 2006), with decrements beginning with the onset of cognitive decline once they reach their mid-sixties (Lau and Redlawsk, 2008). However, from analyses of survey data, both Lau, Anderson, and Redlawsk (2008) and Lau et al. (2013) find that age positively predicts correct voting in real elections, arguing that older voters are better acclimatised to their country's political environment. One possible reconciliation of these findings is that in artificial experiments, older participants have a disadvantage due to deficits in working memory and cognitive flexibility, but that in real world contexts older participants 
Continuous Consistent Voting

benefit from their acclimatisation to, and their previous experience with, their political context.

Partisanship. It is a common but not ubiquitous finding for partisan voters to vote more in accordance with their preferences. To investigate the effects of partisanship, researchers typically assume that any voter who feels close to a party and votes for that party has used the partisan heuristic, which is to vote for the party one feels an attachment towards. These voters can be dummy-coded, and the predictive power of the partisan heuristic inferred from regression (e.g. Lau et al. 2008; Nai, 2015; Joesten \& Stone, 2014). This is a flawed approach however, as no attempt is made to falsify the central claim that these voters adopt the partisan heuristic, when other explanations are plausible - partisans share moral views (Haidt, 2012) and policy preferences with their parties, and it could be these shared preferences which drive their vote. Thus, this approach is likely to overstate the effects of partisanship on vote quality. Furthermore, other research suggests that partisanship diminishes preference-aligned voting - Jessee (2010) finds that non-partisans were more likely to vote in accordance with their preferences than partisans in the 2008 US Presidential election.

Since partisanship is often considered an alternative to policy-based voting (Campbell et al., 1960; Jenke \& Huettel, 2016), it is worth considering to what extent partisan affiliations simply reflect policy agreement. Classic literature argues against this position. In the influential 'Michigan model', partisan political identities were thought to be transmitted from parents to their children arbitrarily, orthogonally to policy considerations (Campbell et al., 1960). It has also been suggested that if there is a relationship between policy preferences and partisanship, it is that voters shift their preferences to match partisan identities (Bartels, 2000). 
Continuous Consistent Voting

However, other scholarship has suggested partisan identities are substantially informed by policy preferences. For one, analysis of historical data suggests that partisan identities are responsive to policy (mis)alignment. When the Democratic party gradually shifted from supporting to opposing anti-Black racist policies in the early-tomid-20 th century (the 'Southern realignment'), Southern whites who had historically identified with the Democrats but stood to lose out from such policies did not shift their policy preferences to suit their partisan identity, but rather gradually dropped their affiliation with the Democrats and turned to the Republican party instead (Fowler, 2020). Similarly, Europhile Conservatives were more likely to disaffiliate following the party's abrupt transition from opposing to supporting Brexit in 2016, than shift their own position on the EU (Schonfield \& Winter-Levy, 2019). In a similar vein, Conservative, Labour and Liberal Democrat voters with more authoritarian preferences were more likely to switch to UKIP between the 2010 and 2015 general elections (Mahieux, Ackland, Karmannaya, Devlin, \& de-Wit, in press), suggesting that they shifted their partisan identities rather than changing their preferences. Partisanship and preferences may affect each other reciprocally, creating an equilibrium whose position can shift depending on contextual factors, such as the importance and visibility of the issue (Carsey and Layman, 2006). Thus when a relationship between partisanship and preference-aligned voting is observed, it is likely some of this covariance can be attributed to citizens simply identifying with parties whose policies and principles they agree with.

\section{Institutional-level predictors}

Number of parties. There is evidence that the number of parties within an electoral system affects levels of preference-aligned voting. Researchers do not typically base these analyses on the raw number of parties that contest an election, 
but the Effective Number of Electoral Parties (“ENEP”) (Dalton, 1985), a measure that accounts not only for the number of parties within a particular system, but also the vote-share of those parties. Lau et al. (2013), Lau et al. (2008), Singh (2010), and Rosema and de Vries (2011) find that citizens make better voting choices within systems with fewer parties, the former two adopting the standard of a correct vote and the latter two the standard of a policy-aligned vote. The explanation given for this phenomenon is that an increasing number of parties increases citizens' 'choice set complexity', making decisions more difficult. Indeed, choice set complexity is a normative determinant of decision-making strategy (Payne, Bettman, \& Johnson, 1993). The demands of remembering and processing diagnostic information, even with the assistance of heuristics, may become excessive with a large number of parties.

However, mathematical models predict these effects would obtain for binary, but not continuous, measures of "correct" voting even among perfectly policy-aligned voters, suggesting they are the product of systematic error when using a binary measure. This follows from the intuition that, with more parties, voters have more chances to 'get it wrong', and so a binary measure, which penalises voters simply for 'getting it wrong', is likely to assign lower scores as the number of parties increases even if their overall accuracy in matching their preferences to parties remains constant, while a continuous measure, which penalises voters in proportion to the size of their 'error', will not. A mathematical and simulation-based proof of such is given in Supplementary Material 1. Accordingly, Boonen et al. (2017) find no influence of ENEP on the ideological congruence between voters and the parties they vote for using a continuous measure of preference alignment, and Wessels and Schmitt 
Continuous Consistent Voting

(2008) find that voters' choices are more influenced by policy-alignment as ENEP increases.

Polarization. Researchers have contended that identifying one's preferencealigned party should be easier when parties are more polarised, or ideologically dispersed. Accordingly, Joesten and Stone (2014) find that US Congressional voters are better able to vote in accordance with their policy preferences when candidates are ideologically polarised and Lau et al. (2013) find that polarised party systems foster higher correct voting, a finding corroborated by Singh (2010) using a policyalignment measure. However, Boonen et al. (2017) find that higher levels of polarisation decrease levels of ideological congruence between parties and their voters in a cross-national comparison. To speculate, the fact that Boonen and colleagues are unique among these studies in using a continuous measure of preference alignment may be instructive. If the distance between parties is greater, then voters may find it easier to pick their optimum party, inflating binary measures of preference alignment. But those who don't pick the optimum will, by definition, opt for parties whose distance is further away from the optimum, deflating continuous measures.

Proportionality. In more proportional electoral systems - where parties who earn $x \%$ of the vote hold closer to $x \%$ of the seats in the legislature - legislatures better reflect the policy preferences of their electorate (Huber \& Powell, 1994; Dalton, 2015; Golder \& Stramski 2010). For instance, Dalton (1985) analysed the 'dyadic correspondences' between the positions of 1979 European Parliament party elites and their supporters along fourteen policy dimensions and the left-right ideological dimension, finding greater proximity in countries with proportional representation systems. 
Continuous Consistent Voting

These results are consistent with Downs' (1957) theory that under proportional systems, parties are incentivised to propose policy packages which closely match the combinations of policies preferred by (groups of) citizens. If a party moves away from one group of voters, another party can encroach into the absented policy space and win their votes instead, disadvantaging the party who shifts. This incentivises policymatching between parties and voters (Cox, 1990).

Where seats are allocated on the basis of single-member district elections, the incentive structure is markedly different (Huber \& Powell, 1994), and this affects levels of voting quality. For parties, such systems incentivise movement towards the position of the median voter and thereby collapse into two-party systems (Duverger, 1954), unless the electorate is polarised (Downs, 1957). Voters' incentives are affected too, with voters often falling under strong incentives to vote for a different party to their true preference. This situation arises, for instance, if a citizen's preferred party, while viable at the national level, has no hope of winning their local constituency's seat. In this case, voters maximise their preferred party's chances of winning the election not by voting for them, but rather by voting for the party which stands the best chance of depriving their preferred party's closest rivals of the seat. In previous elections in Britain, almost $10 \%$ of voters are estimated to engage in 'tactical voting' of this kind (Fieldhouse, Shryane, \& Pickles, 2007).

Therefore, citizens in single-member district elections may experience perverse incentives to vote against the party they truly prefer, thus diminishing the influence of policy preferences over vote choice that would be visible to researchers. These perverse incentives are less likely to obtain in proportional representation systems (Cox \& Shugart, 1996). Incentive structures for both parties and citizens thus suggest that proportional systems should lead to more preference-aligned votes. 
Continuous Consistent Voting

Age of Democracy. Lau et al. (2013) hypothesised that older democracies should show higher levels of correct voting, simply because voters have collectively had more time to understand and adapt to the task demands created by the relevant electoral institutions. This argument glosses over some potential complications however, - for instance, older democracies may possess more antiquated, byzantine institutional structures, for whose complexity time can do little to compensate. Equally, newer democracies may learn from other countries' historic examples, and commission institutions which are maximally conducive to voting quality. Accordingly, Lau et al. (2013) found no evidence that older democracies do produce higher frequencies of correct votes.

Media environment. Media exposure should help citizens to vote correctly by furnishing them with the information they require to do so. Accordingly, at the aggregate level, Lau et al. (2013) find that countries with denser media environments - higher levels of per-capita telephones, televisions, newspapers, radios, and internet subscriptions - show greater correct voting. At the individual level, Baum and Jamison (2006) find that watching 'soft news' programs like Oprah, which periodically contain political content that can be consumed with low cognitive effort, helps Americans to vote correctly.

These findings fit naturally with the hypothesis that information deficits are the predominant cause of incorrect votes: denser media environments facilitate greater propagation of information to citizens, therefore reducing information deficits and incorrect votes. But the media landscape has undergone systematic transformation since the period studied by Lau et al. (2013) (Lewandowsky, Ecker, \& Cook, 2017). The internet, a major source of political information, is awash with misleading political information in the form of disinformation, misinformation, conspiracy theories, fake 
Continuous Consistent Voting

news, deep fakes, bots, and sock puppets (Pomerantsev, 2019). Rather than recognising online misinformation as unreliable, people are alarmingly credulous of misinformation that coheres with their political views (Jerit \& Zhao, 2020). Thus, media density may propagate information deficits as well as resolving them in the present day, rendering the contemporary effect of media density upon preference-aligned voting uncertain.

Personal vote incentives. In some electoral systems, it is parties that citizens vote for, whereas in others it is candidates. Lau et al. (2013) find that high personal vote incentives, that is, the system being strongly candidate-oriented, are negatively predictive of correct voting. The argument here is that the same parties recurrently contest elections, so citizens can recycle information about parties' characteristics over and over again; but candidates are more variable, and therefore citizens must acquire new information for every election cycle, increasing the possibility of information deficits.

Clear lines of responsibility. Citizens' vote choices are influenced by their evaluation of the incumbent government's performance (Fiorina, 1981), yet some institutional arrangements make it difficult for citizens to determine who is responsible for government performance, i.e., coalitions or split control of legislative houses. Lau et al. (2013) show that in situations of unclear responsibility, citizens are less likely to vote correctly.

\section{Summary}

Studies of the causes of preference-aligned voting at the institutional and individual level have revealed some clear findings, as well as some conflicts and ambiguities. Studies using differing samples and methodologies regularly fail to corroborate each other, introducing apparent contradictions that theory and empirical 
Continuous Consistent Voting

work are yet to resolve. In particular, this has rendered the effects of voter age, voter knowledge, system polarisation, system proportionality, and the number of parties unclear.

This study attempts to offer more robust insights into the impact of these factors by conceptually replicating the methodology employed by Lau et al. (2013) to analyse levels of correct voting across world democracies using data from the Comparative Study of Electoral Systems ("CSES"), with two important differences. First, a new measure of continuous correct voting is used. As described above, this measure should provide a more robust test of the role of the Effective Number of Electoral Parties. More generally, it should also provide a more sensitive measure of the 'quality' of people's electoral voting decisions. For instance, whereas the binary correct voting measure previously employed would classify a left-wing citizen who votes for a rightwing party as equally 'incorrect' as one who votes for a centrist party (presuming they both overlook a left-wing party), this measure is sensitive to the discrepancy between each citizen's optimally-consistent choice and the party they do vote for. Therefore the centrist-voting citizen in the preceding example would score more highly. Thus this measure is sensitive to both the size and frequency of inconsistencies in people's voting decisions at the aggregate level. Lau and colleagues noted their measure's inability to do this was a limitation, and discussed the need for a continuous measure such as the one employed here.

Second, the analysis is also extended to include the effect of system proportionality on correct voting. Previous attempts to do this have been limited. For countries with both single-member district ("SMD”) and multi-member district ("MMD”) electoral tiers, the latter being more proportional than the former, Lau and colleagues calculated correct voting scores separately, but did not analyse whether correct voting 
Continuous Consistent Voting

levels differed. This study employs a continuous measure of proportionality for every country, and formally analyses its effect on Continuous Consistency.

\section{Aims and Hypotheses}

The aim of the present study is to conceptually replicate and extend Lau et al. (2013)'s analysis of the individual-level and institutional-level predictors of correct voting, using a continuous measure. They found that correct voting is positively predicted by citizens' political sophistication, age, and efficacy at the individual level. At the institutional level, it is positively predicted by the density of the media environment, incentives to create a personal vote, clear lines of responsibility, and polarization, while being negatively predicted by the effective number of electoral parties ("ENEP"). Additionally, age and the age of democracy interact positively, as do media density and efficacy. For every effect other than that of ENEP, there is no specific reason why the new continuous measure might produce different results, but this remains a possibility, so no specific hypotheses are made as to whether these effects will replicate. Two more-specific aims of the present study are to clarify the effects of ENEP and system proportionality. Given that mathematical models suggest negative effects of ENEP on correct voting would obtain through pure measurement error with a binary measure of correct voting, but not necessarily a continuous measure, it is hypothesised that there will be no effect of ENEP on Continuous Correctness. Although there is some conflicting empirical evidence, the theoretical literature predicts that voters in more proportional systems should be more easily able to vote in accordance with their preferences (e.g. Cox \& Shugart, 1996), leading to the hypothesis that less proportional systems will show lower levels of Continuous Consistency. 


\section{Method}

The method follows Lau et al. (2013) except where noted. Citations for all data sources are included in the 'Data and Analysis' section of the references.

\section{Participants}

Participant data were taken from waves ${ }^{1}$ 1-5 of the CSES; Lau and colleagues investigated waves 1-2. After excluding elections for which the necessary data was not available and excluding participants who did not vote for one of the parties on whom data were available, $N=225,084$, spread between 147 elections from 19962018 across 48 countries.

\section{Dependent variables}

Both the Binary and Continuous Consistency measures were calculated from party-participant dyadic utility scores. The weighted average of three factors was used to determine utility: ideology, performance evaluation, and closeness. Lau and colleagues selected these factors as determinants of vote choice from prior theoretical work, for instance, these factors are featured in the Shanks-Miller model of voter choice (Miller \& Shanks, 1996). All factors were rescaled to range between 0 and 1 , and all weights to range between 0.2 and 1 , before averaging. However, if a respondent did not provide the answers necessary to calculate one factor, that factor was excluded from their utility calculation. The weighting scheme assumes that voters care less about ideology when the parties are more ideologically similar, government performance when the economy is doing well, and closeness to parties if they don't think parties are important.

Ideology. The ideology factor was calculated by taking the directional difference (Rabinowitz \& MacDonald, 1989) between the respondent's ideology and

\footnotetext{
1 The CSES themselves use the term 'modules', but we consider 'wave' to be clearer.
} 
the party's, both expressed on 0-10 left-right scales. With $x_{p}$ the position of the party and $x_{s}$ the position of the participant, this is given by: $\left(x_{p}-5\right)\left(x_{s}-5\right)$. Respondent ideologies were self-reported and party ideologies provided by the native experts who administered the survey in each country. Where ideology scores were missing for a particular party, they were inferred by averaging the ideological positions attributed to them by participants with university degrees ${ }^{2}$. The ideology factor is weighted by the ideological range of the parties running in each election.

Performance Evaluation. If the respondent expresses approval of the government's performance, the evaluation factor is 1 for all incumbents and 0 for all challengers, and the reverse if they disapprove. Incumbency data were included in the CSES from waves $3-5$, but for waves 1-2 this data was abstracted from the Database of Political Institutions. The weight for the performance evaluation factor is the log of the mean absolute difference between the country's GDP change over the preceding year and the country's average annual GDP change over the past decade. This data was taken from the World Bank.

Closeness. The closeness factor was 1 for any party to which the respondent indicated they were 'very close', 2/3 if 'fairly close', 1/3 if 'somewhat close', and 0 for all others. Participants could only indicate closeness to one party. If a respondent indicated being close to a party but failed to indicate how close, they were assigned $2 / 3$, which was the median response. In some cases, participants were pushed to say whether there was any party they felt closer to if they answered the first question negatively. If they specified a party at this stage, this was counted as their close party. In some cases participants could indicate second- and third-choice parties to which

\footnotetext{
2 Where participants' estimates of parties' ideologies could be compared to the expert ratings, participants with university degrees showed a marginally higher correlation $(r=$ $.83)$ than when all participants' ratings were included $(r=.81)$.
} 


\section{Continuous Consistent Voting}

they felt close, but as this data was only available for some elections in waves 1 and 2 , these responses were not considered. This represents a procedural departure from Lau and colleagues. Although their published specification of their approach is lacking detail in places, inspecting the original analysis scripts (shared by the authors) identified around a dozen different ways in which the various questions related to party identification were combined to give a closeness score, with some approaches being slightly different even when the available data is the same. The advantage of the procedure adopted here is that it can be consistently applied. This therefore reflects a choice to conceptually replicate Lau and colleagues' approach in a more consistent and replicable manner, rather than conduct an exact replication of their original methods.

In a further departure from Lau and colleagues method, the closeness factor was weighted by the respondent's 'satisfaction with democracy'. Lau and colleagues weighted this factor by an 'importance of political parties' score combining voters' answers to two questions about the extent to which "Political parties care what voters think" and "Political parties are necessary to make the system work". However, these questions were absent from CSES3-5 (and indeed from CSES2, an anomaly not discussed by Lau and colleagues), so an alternative was required. The only question consistently asked across all five datasets which reflected the importance of political parties was one concerning the respondent's satisfaction with democracy (since the ability to choose among multiple parties is a critical feature of democracy). In CSES1, answers to the satisfaction with democracy question were positively and significantly correlated with the importance of political parties measure, albeit modestly at $r=.22$.

To calculate the two dependent variables, utility scores were first calculated for each party-voter dyad according to the procedure described above. Within the 
Continuous Consistent Voting

resulting set of utility scores, per participant, there is a maximum (Umax), minimum (Umin), and the utility of the party the participant voted for (Uvote). Continuous Consistency is (Uvote - Umin)/(Umax - Umin). To give a clear indication of how this calculation translates utility scores into Continuous Correctness scores, Figure 1 shows the Continuous Correctness scores than can be obtained under all possible combinations of Uvote, Umin and Umax given an arbitrary 1-point utility scale, and defining these combinations in terms of the distance between Uvote and Umin ("distance from min") and the distance between Umax and Uvote ("distance from max"). Scores increase as the utility of a participant's voted parties moves closer to their maximum and further from their minimum. Binary Correctness is 1 if Uvote $=$ Umax, and 0 otherwise.

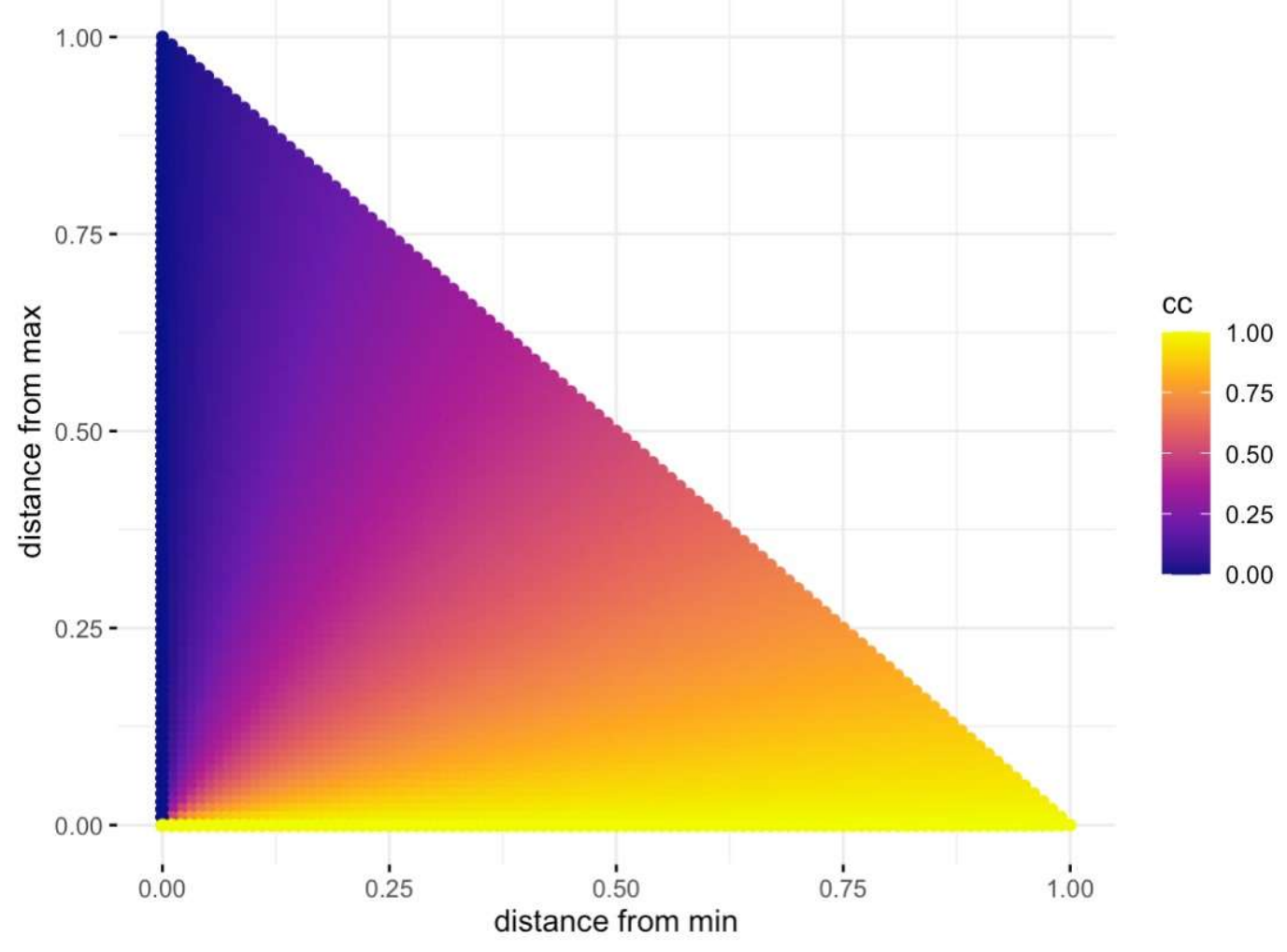

Figure 1. Heatmap of possible Continuous Correctness (cc) scores 
Following Lau et al. (2013), participants score 1 in the event of a tie or if they vote for a party which is allied to their "correct" party, on both measures. Data on alliances were abstracted from the discussions of alliances included in the CSES codebooks and manually coded. In a departure from Lau et al. (2013)'s approach, regional parties which did not run in the participant's region were excluded from that participant's utility set, and therefore did not enter into the calculation of the dependent variables.

\section{Individual-level predictors}

Efficacy. Efficacy was calculated by taking the average response to questions about subjective political efficacy, specifically, to what extent the participant felt it matters who you vote for and who is in power. Higher scores indicate higher efficacy. This is a measure of external efficacy, reflecting citizens' degree of belief that the political system is responsive to their preferences and demands (Acock, Clarke, \& Stewart, 1985).

Age. Age is simply the participant's stated age, or, in CSES3-5, the difference between the election year and their given birth year. Where age data were binned rather than continuous, data from another election which contained continuous data for the same country was used to calculate the median age per bin, and assigned these ages to each respondent.

Political sophistication. Political sophistication was the only measure which could not be consistently measured across CSES1-5. For CSES1-4 it is the equallyweighted average of the respondent's education level (with CSES1-2 data translated to follow the ISCED classification system used in CSES3-4), scaled to $0-1$, and their score on the political knowledge questions - election-specific general political knowledge questions - which is the percentage of questions they answered correctly translated onto a 0-1 scale. For CSES5 the political knowledge questions were not 
Continuous Consistent Voting

asked, and so the measure is education level alone. All analyses were conducted on just the CSES1-4 sample as well as the full sample, and no differences were observed, suggesting this methodological inconsistency is inconsequential. Political sophistication scores were centred within each electoral sample.

Institutional-level predictors

Personal Vote Incentives. Carey and Shugart (1995)'s ordinal measure of institutional incentives to cultivate a personal vote was used, dichotomising this variable such that countries scoring $\geq 10$ were dummy-coded 1 , and others 0 . This was chosen as the dichotomisation point because Lau et al. (2013) identified a "noticeable break in the distribution" at the $71^{\text {st }}$ percentile, and thus adopted it as their dichotomisation point. In this data also the $71^{\text {st }}$ percentile corresponds to a score of 10 for the CSES1-2 (and indeed the full data set).

Clear Lines of Responsibility. Lines of responsibility were classified as clear if, within a Presidential system, the governing party controlled all legislative houses, or, within a Parliamentary system, the governing party had a majority of seats in its own right. These data were taken from the Database of Political Institutions.

Years of Democracy. This variable was calculated by taking the total number of years that a country had scored at least six on the Polity score within the Polity IV data series since 1945. This variable rates the democratic character of global polities on a -10 to +10 scale from autocracy to democracy, with +6 the cut-off point for democracy. The rating is based on six sub-scales: the regulation, competitiveness, and openness of executive recruitment, the competitiveness and regulation of political participation, and constraint on the executive. This variable is logged (base 10).

Effective Number of Electoral Parties. The ENEP for each election was taken by applying Laakso and Taagepera (1979)'s ENEP formula to CSES data on the vote 
Continuous Consistent Voting

shares obtained by each party. In Presidential systems, the Presidential election vote share data was used, and in Parliamentary systems used vote share data for the lower legislative house was used - Lau et al. (2013) do not discuss whether they made such a distinction, but it appears the most valid approach.

Media Density. The source of media density information discussed in Lau et al.'s (2013) supplementary notes was no longer accessible via the provided hyperlinks nor an open search, and so I adopted a maximally similar measure. Using data available from the UN and World Bank, the average number of internet subscriptions, mobile phones, and newspapers per capita in the given electoral year (or the closest available year to the election in question) were used.

Political Polarization. To calculate party polarization, Dalton's (2008) Polarization index formula was applied to the vote share and objective party positions data in the CSES. Thus, this measure of polarization concerns the distribution of party positions along the left-right dimensions rather than any of the many other types of polarization such as the ideological or affective polarization of the electorate.

Proportionality. Proportionality of electoral systems is usually measured on a reverse-scored scale of disproportionality, where higher scores indicate lower proportionality. Disproportionality was measured using Gallagher's (1991) Least Squares index, by abstracting scores from Gallagher's open-source pdf (Gallagher, 2020). The measure for a given election was the average disproportionality scores attained in the country since 1945, following Wessels and Schmitt (2008). Lau et al. (2013) do not use a measure of disproportionality. Although this measure of 'disproportionality' is used in the regression, this is discussed in terms of proportionality in the results and discussion. 
Continuous Consistent Voting

\section{Analysis}

A multi-level regression was performed in Stata to determine the effects of these factors upon Continuous and Binary Consistency. In all cases, the individual-level factors were specified as random-effects and the institutional-level factors as fixedeffects, with the election as the grouping variable. Some countries use 'mixed' electoral systems, where seats in one 'tier' of the lower house are elected by a singlemember district ("SMD”) election and seats in another 'tier' elected by a multimember district ("MMD”) election, giving citizens one vote in each. Where participants' vote data were available for both, they were treated as separate elections by the grouping variable, with participants being randomly assigned between them in proportion to the fraction of seats in each tier (after Lau and colleagues). This random assignment ensures participants are not counted twice in estimating the impact of different demographic factors. Similarly, where Presidential elections involve two rounds and vote data was available for each, they were treated as separate elections, with participants evenly and randomly split between rounds. Robust standard errors were used to correct for heteroskedasticity and the institutional-level predictors were centred before analysis. Additionally, observations were weighted by election-specific sample weights provided in the CSES to achieve representativeness.

Four models were analysed to illuminate whether any differences between this study and Lau et al. (2013)'s results are due to our different dependent variables, different samples, different covariates, or methodological differences. As well as a (marginally) 'expanded' model incorporating proportionality as a factor, an 'original' model which only contains Lau et al. (2013)'s covariates was analysed using Continuous Consistency as the dependent variable. This model was also tested with Binary Consistency as the dependent variable, with both the full CSES1-5 sample and a CSES1-2 sample to match Lau et al. (2013). 


\section{Results}

Figure 2 depicts the distribution of Continuous and Binary Consistency scores obtained across all elections, for (see Appendix for numerical data for each election separately). As shown, Binary Correctness scores (Mean $=0.682$ (95\% Cl: 0.681$0.684)$, Median = $0.693($ IQR: 0.619-0.784)), consistently underestimate Continuous Correctness scores $($ Mean $=0.805(95 \%$ Cl: 0.808-0.811), Median $=0.814($ IQR: 0.769-0.855)), suggesting that although citizens do make voting 'errors', these are generally between similarly positioned parties or candidates. Table 1 shows the results from four regression models: two models with continuous consistency as dependent variable, one featuring disproportionality as a predictor and one not, and two models with binary consistency as dependent variable, one with the full five waves' sample, one with just the first two waves to match and therefore permit a direct comparison to Lau et al. (2013).

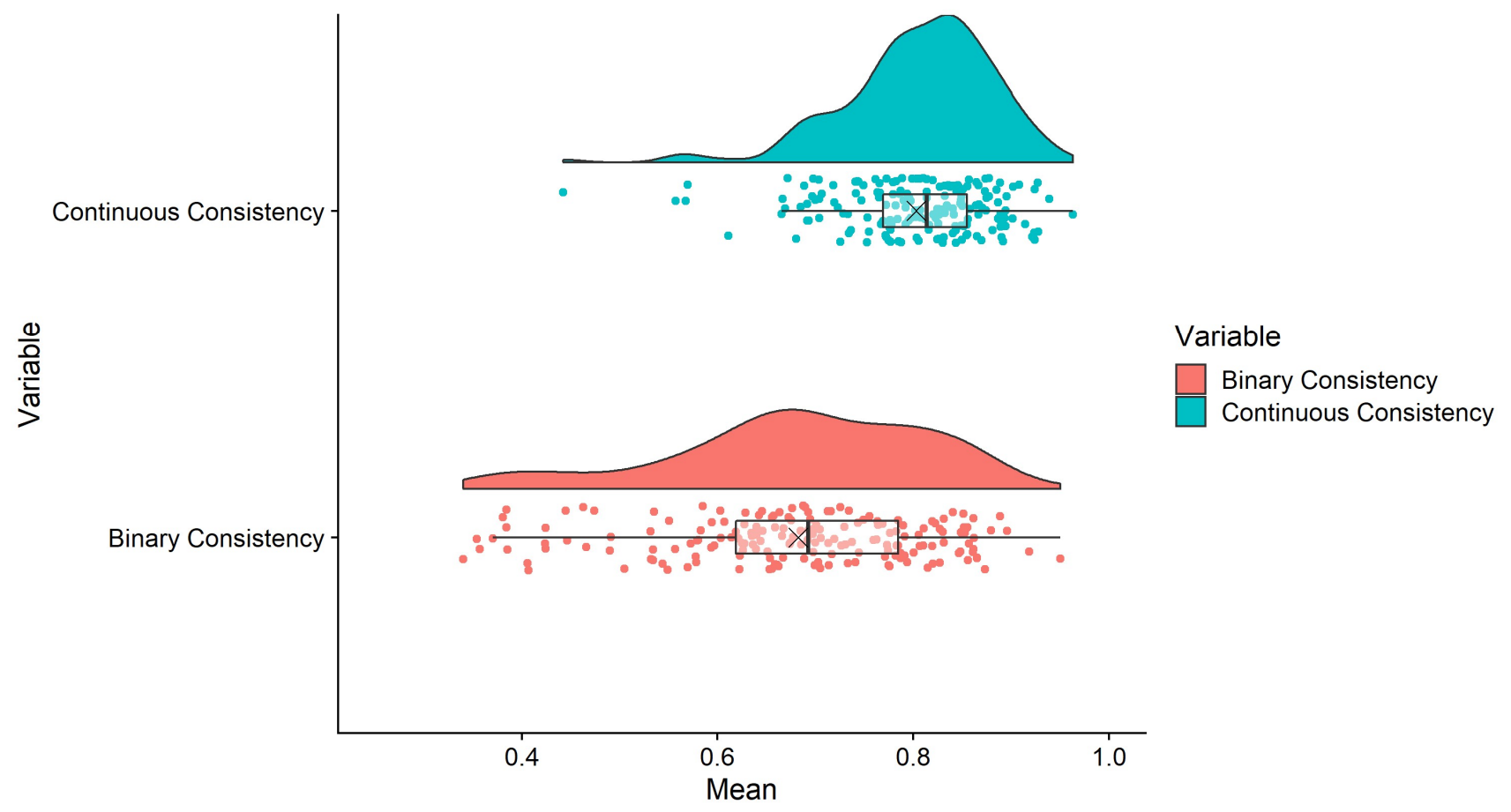

Figure 2. Raincloud plots of Continuous and Binary Consistency Scores 
Continuous Consistent Voting

Table 1 Consistent voting multi-level regression models

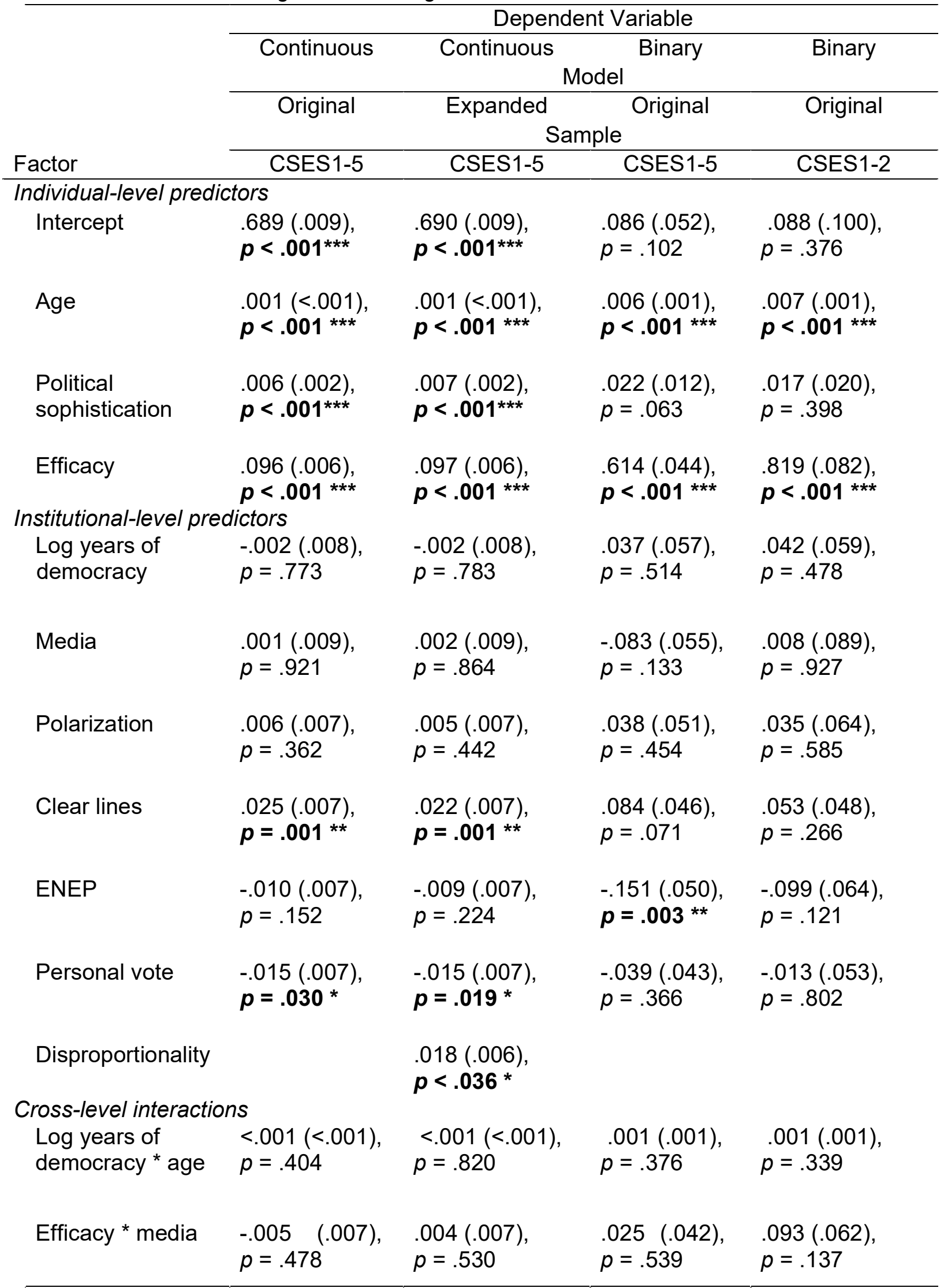


Continuous Consistent Voting

\begin{tabular}{|c|c|c|c|c|}
\hline \multirow[b]{4}{*}{ Factor } & \multicolumn{4}{|c|}{ Dependent Variable } \\
\hline & \multicolumn{4}{|c|}{ Model } \\
\hline & Original & Expanded & mple & Original \\
\hline & CSES1-5 & CSES1-5 & CSES1-5 & CSES1-2 \\
\hline \multicolumn{5}{|c|}{ Individual-level variance } \\
\hline Intercept & $.006(.001)$ & $.005(.001)$ & $.149(.051)$ & $.241(.032)$ \\
\hline Age & $<.001(<.001)$ & $<.001(<.001)$ & $<.001(<.001)$ & $<.001(<.001)$ \\
\hline $\begin{array}{l}\text { Political } \\
\text { sophistication }\end{array}$ & $<.001(<.001)$ & $<.001(<.001)$ & $.018(.004)$ & $.015(.002)$ \\
\hline Efficacy & $.003(.001)$ & $.003(<.001)$ & $.164(.037)$ & $.188(.031)$ \\
\hline Residual & $.114(.003)$ & $.113(.003)$ & & \\
\hline
\end{tabular}

Note: Cells show standardised coefficients, standard errors in parentheses, and p-values. $p<.0125^{*}, p<.01^{* *}, p<.001^{* * *}$ 
Continuous Consistent Voting

\section{Discussion}

Mean levels of Continuous Consistency are high - over .8 in a majority of elections. Thus, most electorates vote for parties at least $80 \%$ as "correct" as possible on average. A robust pattern of predictors emerges across the four regression models: age and efficacy are consistently positively predictive of consistent voting, whereas the age of the democracy, media density, party polarisation, and the two cross-level interactions are never predictive. Additionally, disproportionality is predictive when included in the continuous model, and does not alter the significance of any other effects. Clear lines of responsibility and political sophistication are both positively predictive in the continuous models only, whereas personal vote incentives are negatively predictive in the continuous models only. ENEP is negatively predictive in the CSES1-5 binary model only. Additional robustness checks were carried out (see Supplementary Materials 2) which corroborate this pattern, but for suggesting the true effect of disproportionality may be null.

Therefore the results obtained using the continuous measure of consistency are substantially different to those obtained by Lau et al. (2013). Of ten significant effects identified by Lau and colleagues, only five retain significance when a continuous measure of consistency is used. These different results cannot be entirely attributed to the different dependent variable, however. The most direct replication of Lau and colleagues' approach, applying the original model to CSES1-2 data with Binary Consistency as the dependent variable, only replicates two out of ten significant predictors (for Lau and colleagues, all except years of democracy were significant). This suggests the small differences between this study's and Lau and colleagues' methodological approach are important. Methodological deviation has been reduced as far as possible, but on occasion was impossible to avoid, clearly preferable, or 


\section{Continuous Consistent Voting}

necessitated by the need for a consistent analytic approach across the five CSES waves. The contribution of party-closeness information to this study's determination of the "correct"/consistent vote is likely to be quite different to Lau et al. (2013)'s since the closeness factor is calculated and weighted differently, though it is not possible to determine analytically to what extent this can account for the differential findings. Certainly these differences represent a limitation for this study vis-à-vis its attempt to conceptually replicate, and bear upon the reliability of, Lau et al. (2013); but they do not diminish the appropriateness of this study's analysis strategy in its own right.

Both models of Continuous Consistency find that ENEP has null effects, though it has a negative effect on Binary Consistency in one model. This is consistent with our suggestion that binary measures of 'correct' or consistent voting are likely to artificially inflate the effects of the number of parties. The absence of evidence for an effect is not evidence for the absence of an effect, however, and so this result should not be treated as definitive. Nevertheless, this finding strengthens the argument that effects of ENEP on preference-aligned voting are likely artefactual. Why, then, does increasing ENEP not diminish preference-alignment due to increased choice set complexity, as supposed by previous literature (Lau et al., 2013)? One explanation might be that voters choose for whom to vote in a two-stage process, first narrowing down the number of parties to a 'consideration set' using broad, salient criteria, then making their final decision from among this set using finer judgment (Oscarsson \& Oskarson, 2019). Therefore, increasing ENEP might, for many voters, only increase the number of parties they don't consider. Thus, their veridical choice set is not enlarged by increasing ENEP, meaning the true effect of ENEP on choice complexity is flat. Future studies could investigate this possibility by comparing ENEP directly with the number of parties voters themselves report they would consider voting for. 
Continuous Consistent Voting

More proportional democracies were hypothesized to have higher levels of Continuous Consistency. The results provide evidence for the opposite effect - less proportional systems had higher levels of correct voting. What can explain this unexpected finding? One possibility is that proportional systems possess broader institutional differences which make it harder for citizens to vote in accordance with their preferences. To test whether proportionality affects preference-aligned voting independently of any such broader institutional influences, single-member district (disproportional) and multi-member district (proportional) elections were compared within those countries which use a mixed system in a post-hoc analysis. This creates a natural quasi-experiment, as all institutional factors except proportionality are controlled. In contrast to the approach for the multi-level regressions, participants were not assigned to either the single-member district or the multi-member district election, but all participant data for both are included. Figure 3 shows that "Continuous Correct Voting" is generally higher in multi-member district elections. A one-way ANOVA shows that the difference in the mean levels of Continuous Correctness between single-member district elections (.781 \pm SD .356) and multi-member district elections $(.805 \pm$ SD .344$)$ is significant $(F(1,62,528)=72.571, p<.001$, Cohen's $f=.03)$, albeit with a very small effect size (this pattern is corroborated by the additional checks in Supplementary Materials 2). This suggests that the effect of proportionality upon correct voting itself is positive but that other institutional factors which covary with proportionality mask this effect. 


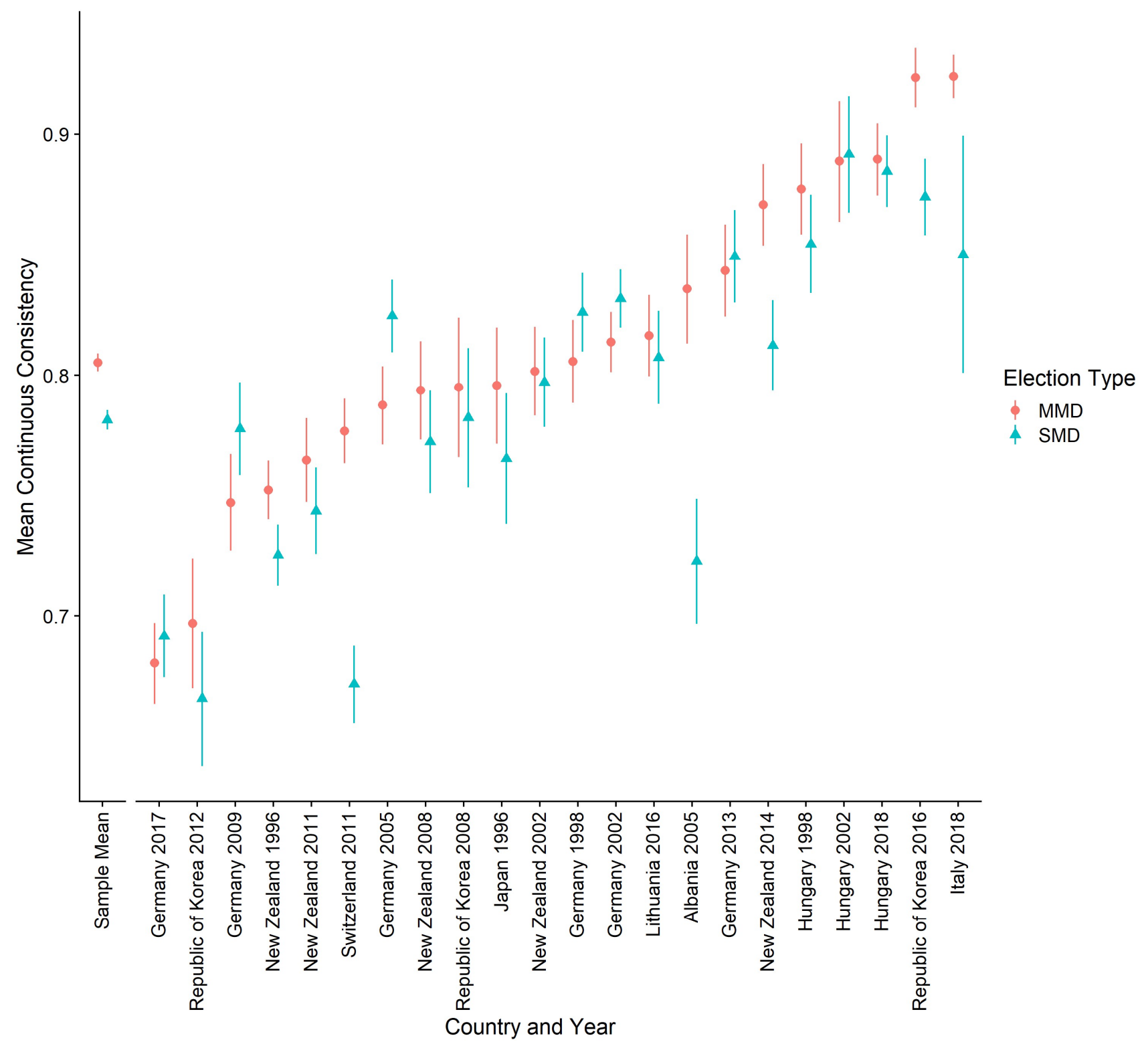

Figure 3. Mean Continuous Consistency scores between single-member and multimember district elections, with 95\% confidence intervals.

One important caveat to the finding that consistent voting levels are lower in countries with proportional systems is that, as previously discussed, this is a measure of relative preference optimisation, measuring how much closer people's voted-parties are to the best available party given their own preferences than the worst party, rather than absolute optimisation, which measures how close people's voted-parties are to 


\section{Continuous Consistent Voting}

their own preferences along some informative pre-defined scale. There is evidence that absolute preference optimisation is higher in proportional systems. For instance, Huber and Powell (1994) find that under proportional systems, the average position of government parties is closer to the median voter on a 1-10 ideology scale than majoritarian systems. It may be that when parties are located closer to voters in absolute terms, voters can afford to relax preferences for relative alignment, since even a less-aligned party in relative terms may be very close in absolute terms. This is another potential explanation for the decreasing levels of correct voting in proportional systems - voters simply do not need to care so much about voting consistently in order to optimise absolute alignment. Whether increased absolute alignment effectively compensates and accounts for lower correct voting in proportional systems is a testable hypothesis, but not with the current data as the party closeness and evaluation factors are not measured on absolute scales for every party. Future studies should address whether the pattern of results regarding proportionality and correct voting is better explained by institutional factors that covary with proportionality or the fact that proportional systems typically have higher absolute alignment.

Government systems which provide clear lines of responsibility, and therefore allow citizens to accurately assign blame and credit to political parties for government performance, enhance citizens' ability to vote consistently with their preferences. Since one of the preferences we consider is the citizen's evaluation of their government's performance, it makes sense that when citizens can better identify which parties are responsible for government performance, they can better integrate these evaluations into their voting decisions appropriately. More generally, having clearer feedback on which parties are responsible for which aspects of government 
Continuous Consistent Voting

performance should help citizens learn more about parties' strengths, weaknesses, and ideologies, as these should all be embodied in their contribution to government performance.

Government systems which incentivise politicians to cultivate personal votes, i.e. systems whose elections are focussed more on candidates than parties, decrease the consistency of citizens' votes. This is consistent with the idea that reasoning about parties can be more efficient than reasoning about candidates, since information about parties can be reliably recycled election-by-election, whereas it is more burdensome for citizens to remember an equivalent amount of information about a range of candidates who vary election-by-election.

At the individual-level, positive effects of political sophistication are consistent with the majority of the literature which finds that better-informed citizens are better able to vote in accordance with their preferences (Rapeli, 2018). Although the political sophistication variable was calculated differently for wave 5 compared to waves 1-4, owing to no political knowledge questions having been asked, an additional regression analysis of just the waves 1-4 data also found that political sophistication was positively predictive of continuous consistent voting, both with and without including disproportionality as a predictor (both $\mathrm{B}=.007, \mathrm{SE}=.002, \mathrm{p}<.001$ ). The strongest robust predictor of Continuous Consistency is political efficacy, which here measures external efficacy. Thus citizens vote more in accordance with preference when they believe the government is responsive to those expressions of preference. This suggests citizens are more likely to invest the effort required to vote "correctly" when doing so appears to be worthwhile. However, it is also not impossible that the direction of causality is reversed, with voters who typically vote more consistently coming to feel 
Continuous Consistent Voting

more self-efficacious. Future longitudinal studies would be needed assess the direction of causality.

Age is also a significant predictor of Continuous Correctness, but with a very small effect (beta $=0.001)$. This effect has been previously attributed to age's affordance of greater experience with the political system (Lau et al., 2013), although other studies have found age to be negatively predictive of correct voting (Lau and Redlawsk, 2008). It is noteworthy that the effects of age and efficacy are robust across every version of this analysis, so this work adds weight to the interpretation that these are robust predictors of both binary and continuous "Correct Voting".

\section{Conclusions}

This study provides a solution to an outstanding methodological issue in the "correct" voting literature, by introducing a new measure of "correct" voting Continuous Consistency. This measure allows for a more sensitive and valid assessment of how levels of "correct" voting differ between individuals and political systems. Additionally, this measure allows for a less-biased assessment of the effect of the number of parties on electoral decision-making. The most striking result of this study is the high level of average correctness achieved by voters - at least $80 \%$ in most elections. This suggests that while voters do not always vote for the party who most satisfies their preferences, their choices rarely stray too far from the ideal. While even small voting 'errors' can of course lead to very different electoral outcomes, given that all political candidates are different, this accuracy is remarkably high given the complexity of voting decisions, and suggests voters' strategies for managing and responding to that complexity are highly effective. In contrast to growing concerns about the irrationality of individual voters, this finding suggests that 
Continuous Consistent Voting

voters are actually quite competent at making a choice consistent with their preferences given the options available to them, within a particular electoral context.

Given the discrepancies between the results obtained in this study and Lau et al. (2013), some uncertainty remains as to what institutional and individual-level factors affect the consistency of citizens' votes with their political preferences. But some findings appear robust. In particular, a range of individual factors (political sophistication, age, efficacy) are all highly robust predictors of voting consistently. Among the institutional factors, systems which provide clear lines of responsibility help citizens to vote consistently, systems with candidate-focussed 'personal vote' incentives rather than party-focussed elections hinder this effort, whereas the number of parties does not affect levels of correct voting. Proportionality has countervailing effects upon correct voting - systems with higher proportionality show lower levels of correct voting (though robustness checks suggest this effect may truly be null), but within individual countries, elections held under proportional rules typically result in more preference-consistent votes, albeit with a very small effect (though one supported by robustness checks).

\section{Data Availability Statement}

Replication files: davidjyoung/ContinuousConsistentVoting (github.com)

\section{Supplementary Material}

All supplementary materials: davidjyoung/ContinuousConsistentVoting (github.com)

\section{Competing Interests}

The authors declare no competing interests.

\section{Acknowledgments}

We thank Richard Lau for his assistance in providing material related to Lau et al. (2013) 
Continuous Consistent Voting

\section{References}

Acock, A. C., Clarke, H. D., \& Stewart, M. C. (1985). A New Model for Old Measures: A Covariance Structure Analysis of Political Efficacy. Journal of Politics, 47, 1061-84.

Baldasarri, D. (2012). The Simple Art of Voting: The Cognitive Shortcuts of Italian Voters. Oxford: Oxford University Press.

Bandura A. (1989). Human Agency in Social Cognitive Theory. The American Psychologist, 44(9), 1175-1184.

Bartels, L. M. (2000). Partisanship and Voting Behavior, 1952-1996. American Journal of Political Science, 44(1), 35-50.

Baum, M. \& Jamison, A. (2006). The Oprah Effect: How Soft News Helps Inattentive Citizens Vote Consistently. Journal of Politics, 68(4), 946-59.

Blais, A. \& Bodet, M. (2006). Does Proportional Representation Foster Closer Congruence Between Citizens and Policy Makers? Comparative Political Studies, 39(10), 1243-1262.

Boonen, J., Pedersen, E. F., \& Hooghe, M. (2017). The Effect of Political Sophistication and Party Identification on Voter-Party Congruence. A Comparative Analysis of 30 Countries. Journal of Elections, Public Opinion, and Parties, 27(3), 311329.

Campbell, A., Gurin, G., \& Miller, W. E. (1954). The Voter Decides. Row, Peterson, and Co..

Campbell, A., Converse, P., Miller, W., \& Stokes, D. (1960). The American Voter. New York: Wiley. 
Continuous Consistent Voting

Campbell, D., Green, J., \& Layman, G. (2011). The Party Faithful: Partisan Images, Candidate Religion, and the Electoral Impact of Party Identification. American Journal of Political Science, 55(1), 42-58.

Carey, J. M. \& Shugart, M. S. (1995). Incentives to Cultivate a Personal Vote: A Rank Ordering of Electoral Formulas. Electoral Studies, 14(4), 417-439.

Carsey, T. M. \& Layman, G. C. (2006). Changing Sides or Changing Minds? Party Identification and Policy Preferences in the American Electorate. American Journal of Political Science, 50(2), 464-477.

Conover, P. J., \& Feldman, S. (1989). Candidate Perception in an Ambiguous World: Campaigns, Cues, and Inference Processes. American Journal of Political Science, 33, 912-940.

Converse, P. (1964). The Nature of Belief Systems in Mass Publics. In D. Apter (ed.), Ideology and Discontent. New York: Free Press of Glencoe.

Cox, G. (1990). Centripetal and Centrifugal Incentives in Electoral Systems. American Journal of Political Science, 34, 903-935.

Cox, G. W. \& Shugart, M. S. (1996). Strategic Voting Under Proportional Representation. The Journal of Law, Economics, and Organization, 12(2), 299-324. Dalton, R. J. (1985). Political Parties and Political Representation: Party Supporters and Party Elites in Nine Nations. Comparative Political Studies, 18(3), 267-299.

Dalton, R. J. (2008). The Quantity and Quality of Party Systems: Party System Polarization, Its Measurement, and Its Consequences, Comparative Political Studies, 41(7), 899-920.

Dalton, R. J. (2015). Party Representation Across Multiple Issue Dimensions. Party Politics, 23(6), 609-622. 
Continuous Consistent Voting

Delli Carpini, M. X., \& Keeter, S. (1996). What Americans Know About Politics and Why It Matters. New Haven: Yale University PressDowns, A. (1957). An Economic Theory of Political Action in a Democracy. The Journal of Political Economy, 65(2), 135-150.

Fieldhouse, E., Shryane, N., \& Pickles, A. (2007). Strategic voting and constituency context: Modelling party preference and vote in multiparty elections. Political Geography, 26(2), 159-178.

Foa, R. S., Klassen, A., Slade, M., Rand, A., \& Collins, R. (2020) The Global Satisfaction with Democracy Report 2020. Cambridge, United Kingdom: Centre for the Future of Democracy

Fowler, A. (2020). Partisan Intoxication or Policy Voting? Quarterly Journal of Political Science, 15, 141-179.

Gallagher, M. (1991). Proportionality, Disproportionality, and Electoral Systems. Electoral Studies, 10(1), 33-51.

Golder, M. \& Stramski, J. (2010). Ideological Congruence and Electoral Institutions. American Journal of Political Science, 54(1), 90-106.

Goren, P. (2013). On Voter Competence. Oxford: Oxford University Press. Huber, J. D. \& Powell, G. B. Jr. (1994). Congruence Between Citizens and Policymakers in Two Visions of Liberal Democracy. World Politics, 46(3), 291-326.

Jackman, S. \& Sniderman, P.M. (2002). Institutional Organization of Choice Spaces: A Political Conception of Political Psychology. In Monroe, K. R. (Ed.) Political Psychology. 209-224. Mahwah, NJ: Lawrence Erlbaum Associates. Jenke, L. \& Huettel, S. A. (2016). Issues or Identity? Cognitive Foundations of Voter Choice. Trends in cognitive sciences, 20(11), 794-804. 
Continuous Consistent Voting

Jerit, J. \& Zhao, Y. (2020). Political Misinformation. Annual Review of Political Science, 23(1), 77-94.

Jessee, S. (2010). Partisan Bias, Political Information and Spatial Voting in the 2008 Presidential Election. Journal of Politics, 72, 327-340.

Joesten, D. A. \& Stone, W. J. (2014). Reassessing Proximity Voting: Expertise, Party, and Choice in Congressional Elections. The Journal of Politics, 76(3), 740743. Jost, J. T. (2006) The End of the End of Ideology. American Psychologist, 61(7), 651-670. 10.1037/0003-066X.61.7.651

Jost, J. T., Glaser, J., Kruglanski, A. W., \& Sulloway, F. J. (2003).

Political conservatism as motivated social cognition. Psychological bulletin, 129(3), 339.

Todorov, A., Mandisodza, A. N., Goren, A., \& Hall, C. C. (2005). Inferences of competence from faces predict election outcomes. Science, 308(5728), 1623-1626.

Kahneman, D. (2011). Thinking, Fast and Slow. London: Penguin Books.

Kuklinski, J. H. \& Quirk, P. J. (2000). Reconsidering the Rational Public: Cognition, Heuristics, and Mass Opinion. In Lupia, A., McCubbins, M. D. , \& Popkin, S. L. (Eds.), Elements of Reason: Cognition, Choice, and the Bounds of Rationality. Cambridge: Cambridge University Press. 153-182.

Laakso, M. \& Taagepera, R. (1979). "Effective" Number of Parties. A Measure with Application to West Europe. Comparative Political Studies, 12(1), 3-27.

Lau, R.R. \& Redlawsk, D.P. (1997). Voting Correctly. American Political Science Review, 91(3), 585-98.

Lau, R. R. \& Redlawsk, D. P. (2006). How Voters Decide: Information Processing during Election Campaigns. New York: Cambridge University Press. 
Continuous Consistent Voting

Lau, R. R., Andersen, D. J., \& Redlawsk, D. P. (2008). An Exploration of Correct Voting in Recent U.S. Presidential Elections. American Journal of Political Science, 52(2), 395-411.

Lau, R. R. \& Redlawsk, D. P. (2008). Older but Wiser? Effects of Age on Political Cognition. The Journal of Politics, 70(1), 168-185.

Lau, R. R., Patel, P., Fahmy, D. F., \& Kaufman, R. R. (2013). Correct Voting Across Thirty-Three Democracies: A Preliminary Analysis. British Journal of Political Science, 44(2), 239-59.

Lau, R. R., Kleinberg, M. S., Ditonto, T. M. (2018) Measuring Voter Decision Strategies in Political Behavior and Public Opinion Research. Public Opinion Quarterly, 82, 911-936.

Lewandowsky, S., Ecker, U. K. H., \& Cook, J. (2017). Beyond Misinformation: Understanding and Coping with the "Post-Truth" Era. Journal of Applied Research in Memory and Cognition, 6, 353-369.

Mahieux, E., Ackland, J., Karmannaya, E., Devlin, J., \& de-Wit, L. H. (in press) What flips the switch? Exploring the psychological factors behind vote switching. Mill, J. S. (1859 [1962]) On Liberty. In Warnock, M. (Ed.) Utilitarianism. Glasgow: William Collins Sons \& Co. Ltd.

Miller, W. E., \& Shanks, J. E. (1996). The New American Voter. Cambridge, MA: Harvard University Press.

Nai, A. (2015). The Maze and the Mirror: Voting Correctly in Direct Democracy. Social Science Quarterly, 96(2), 465-86.

Oscarsson, H. \& Oskarson, M. (2019). Sequential Vote Choice: Applying a Consideration Set Model of Heterogeneous Decisions Processes. Electoral Studies, 57, 275-283. 
Continuous Consistent Voting

Payne, J. W., Bettman, J. R., \& Johnson, E. J. (1993). The Adaptive Decision Maker. Cambridge University Press.

Plato (1952). Republic, trans. Waterfield, R. Oxford: Oxford World's Classics.

Popkin, S.L. (1991). The Reasoning Voter: Communication and Persuasion in Presidential Campaigns. Chicago: University of Chicago Press.

Rabinowitz, G. \& Macdonald, S.E. (1989). A Directional Theory of Issue Voting. American Political Science Review, 83(1), 93-121.

Rapeli, L. (2018). Does Sophistication Affect Electoral Outcomes? Government and Opposition, 53(2), 181-204.

Rosema, M. \& de Vries, C. E. (2011). Assessing the Quality of European Democracy: Are Voters Voting Correctly? In Rosema, M., Denters, B., \& Aarts, K. (Eds.). How Democracy Works: Political Representation and Policy Congruence in Modern Societies. Amsterdam University Press.

Schonfeld, B. and Winter-Levy, S., (2019). Policy or Partisanship in the United Kingdom? Quasi-Experimental Evidence from Brexit. Journal of Politics, Forthcoming, Available at SSRN: https://ssrn.com/abstract $=3373348$ or http://dx.doi.org/10.2139/ssrn.3373348

Simas, E. N. (2013). Proximity Voting in the 2010 U.S. House Elections. Electoral Studies, 32(4), 708-717.

Simon, H. A. (1985). The Dialogue of Psychology with Political Science. The American Political Science Review, 79(2), 293-304.

Simon, H. A. (1995). Rationality in Political Behavior. Political Psychology, 16(1), 4561.

Singh, S. P. (2010). Contextual Influences on the Decision Calculus: A CrossNational Examination of Proximity Voting. Electoral Studies, 29, 425-434. 
Continuous Consistent Voting

Sniderman, P. M., Brody, R. A., Tetlock, P.E. (1991). Reasoning and Choice:

Explorations in Political Psychology. Cambridge: Cambridge University Press

Sokhey, A.E. \& McClurg, S.D. (2012). Social Networks and Correct Voting. Journal of Politics, 74(3), 751-64.

Steenbergen, M. R., \& Colombo, C. (2018). Heuristics in Political Behavior. In Mintz, A., Terris, L. (Eds.), The Oxford Handbook of Behavioral Political Science.

Oxford, UK: Oxford University Press.

Todd, P. M. \& Gigerenzer, G. (2000). Simple Heuristics that Make us Smart (Précis). Behavioral and Brain Sciences, 23, 727-741.

Van Bavel, J. J. \& Pereira, A. (2018). The Partisan Brain: An Identity-Based Model of Political Belief. Trends in Cognitive Sciences, 22(3), 213-224.

Wessels, B. \& Schmitt, H. (2008). Meaningful Choices, Political Supply, and Institutional Effectiveness. Electoral Studies, 27, 19-30. 
Continuous Consistent Voting

\section{Data and Analysis Sources}

Requested citations used where provided.

Incentives to Cultivate a Personal Vote: Johnson, J. W. \& Wallack, J. S. (2012).

Electoral Systems and the Personal Vote. Harvard Dataverse, V1. Retrieved from:

https://dataverse.harvard.edu/dataset.xhtml?persistentld=doi:10.7910/DVN/AMRXJA

\section{Comparative Study of Electoral Systems:}

Module 1: Comparative Study of Electoral Systems Secretariat. COMPARATIVE STUDY OF ELECTORAL SYSTEMS, 1996-2001 [Computer file]. 4th ICPSR version. Ann Arbor, MI: University of Michigan, Center for Political Studies [producer], 2002. Ann Arbor, MI: Inter-university Consortium for Political and Social Research [distributor], 2004. Sapiro, V, and Shively, W. P. Comparative Study of Electoral Systems, 2001-2006. Ann Arbor, MI: Inter-university Consortium for Political and

Module 2: Social Research [distributor], 2008-07-01.

https://doi.org/10.3886/ICPSR03808.v2

Module 3: The Comparative Study of Electoral Systems (www.cses.org). CSES MODULE 3 FULL RELEASE [dataset]. December 15, 2015 version. doi:10.7804/cses.module3.2015-12-15

Module 4: The Comparative Study of Electoral Systems (www.cses.org). CSES MODULE 4 FULL RELEASE [dataset]. May 29, 2018 version. doi:10.7804/cses.module4.2018-05-29

Module 5: The Comparative Study of Electoral Systems (www.cses.org). CSES MODULE 5 FIRST ADVANCE RELEASE [dataset]. May 21, 2019 version. doi:10.7804/cses.module5.2019-05-21

Database of Political Institutions: Cruz, C., Keefer, P., \& Scartascini, C. (2018). 
Continuous Consistent Voting

Database of Political Institutions 2017 (DPI2017). Inter-American Development

Bank. Numbers for Development. https://mydata.iadb.org/Reform-Modernization-

ofthe-State/ Database-of-Political-Institutions-2017/938i-s2bw

Gallagher (2020) Least Squares Index pdf:

https://www.tcd.ie/Political Science/people/michael gallagher/EISystems/Docts/Elec

$\underline{\text { tionlndices.pdf }}$

Media Density data:

Internet: $\quad$ Fixed Broadband Subscriptions (per 100 people). [dataset].

World Bank. International Telecommunication Union, World

Telecommunication/ICT Development Report and database.

Retrieved from:

https://data.worldbank.org/indicator/IT.NET.BBND.P2

Mobiles phones: Mobile cellular subscriptions (per 100 people). [dataset]. World

Bank. International Telecommunication Union, World

Telecommunication/ICT Development Report and database.

Retrieved from:

https://data.worldbank.org/indicator/IT.CEL.SETS.P2

Newspapers: $\quad$ Daily newspapers: Total Average Circulation per 1000

Inhabitants. [dataset]. UNESCO Institute for Statistics. Retrieved from:

http://data.un.org/Data.aspx?d=UNESCO\&f=series\%3AC_N_C

DN

Polity IV: Marshall, M. G. \& Gurr, T. R. (2013). Polity IV Project: Political Regime

Characteristics and Transitions, 1800-2013. Political Instability Task Force (Central 
Continuous Consistent Voting

Intelligence Agency). Retrieved from:

https://www.systemicpeace.org/polity/polity4.htm

World Bank GDP data: GDP growth (annual \%). World Bank National Accounts

Data, and OECD National Accounts Data Files. Retrieved from:

https://data.worldbank.org/indicator/NY.GDP.MKTP.KD.ZG

All data analysis and processing except for the multi-level regression, which was conducted using Stata, was conducted using $\mathrm{R}$

R Core Team (2019). R: A language and environment for statistical computing. $R$ Foundation for Statistical Computing, Vienna, Austria. URL https://www.Rproject.org/.

StataCorp. (2019). Stata Statistical Software: Release 16. College Station, TX: StataCorp LLC. 
Continuous Consistent Voting

Appendix

Consistency Scores in Descending Order of Mean Continuous Consistency

\begin{tabular}{|c|c|c|c|c|c|c|}
\hline \multirow[b]{3}{*}{ Country } & \multirow[b]{3}{*}{ Year } & \multicolumn{4}{|c|}{ Measures of Consistency } & \multirow[b]{3}{*}{$\mathrm{n}$} \\
\hline & & \multicolumn{2}{|c|}{ Continuous } & \multicolumn{2}{|c|}{ Binary } & \\
\hline & & Mean & SD & Mean & SD & \\
\hline Taiwan & 2004 & 0.963 & 0.181 & 0.95 & 0.218 & 1823 \\
\hline Spain & 2000 & 0.939 & 0.23 & 0.918 & 0.274 & 1208 \\
\hline Czech Republic & 2002 & 0.928 & 0.219 & 0.861 & 0.347 & 948 \\
\hline Mexico & 2006 & 0.927 & 0.222 & 0.862 & 0.345 & 1591 \\
\hline Italy & 2018 (MMD) & 0.924 & 0.214 & 0.823 & 0.382 & 4002 \\
\hline Republic of Korea & 2016 (MMD) & 0.924 & 0.237 & 0.879 & 0.326 & 2398 \\
\hline Poland & 2007 & 0.924 & 0.227 & 0.848 & 0.359 & 1817 \\
\hline United States & 2004 & 0.921 & 0.255 & 0.896 & 0.306 & 1066 \\
\hline Uruguay & 2009 (Round 1) & 0.914 & 0.242 & 0.851 & 0.356 & 968 \\
\hline Spain & 2004 & 0.908 & 0.266 & 0.831 & 0.375 & 1212 \\
\hline Australia & 2004 & 0.902 & 0.273 & 0.846 & 0.361 & 1769 \\
\hline Spain & 2008 & 0.901 & 0.276 & 0.862 & 0.346 & 1204 \\
\hline Switzerland & 1999 & 0.895 & 0.269 & 0.815 & 0.389 & 2048 \\
\hline Turkey & 2011 & 0.894 & 0.227 & 0.689 & 0.463 & 1109 \\
\hline Canada & 2011 & 0.894 & 0.28 & 0.865 & 0.342 & 3458 \\
\hline South Africa & 2009 & 0.893 & 0.271 & 0.807 & 0.395 & 1200 \\
\hline Hungary & 2002 (SMD) & 0.892 & 0.291 & 0.853 & 0.355 & 1200 \\
\hline Czech Republic & 1996 & 0.89 & 0.271 & 0.79 & 0.408 & 1229 \\
\hline Hungary & 2018 (MMD) & 0.89 & 0.283 & 0.82 & 0.384 & 2416 \\
\hline Canada & 2015 & 0.889 & 0.28 & 0.852 & 0.356 & 4202 \\
\hline Hungary & 2002 (MMD) & 0.889 & 0.296 & 0.857 & 0.351 & 1200 \\
\hline United States & 2012 & 0.889 & 0.314 & 0.889 & 0.314 & 1929 \\
\hline Italy & 2006 & 0.887 & 0.299 & 0.861 & 0.346 & 1439 \\
\hline Australia & 1996 & 0.886 & 0.288 & 0.831 & 0.375 & 1798 \\
\hline Hungary & 2018 (SMD) & 0.885 & 0.281 & 0.8 & 0.4 & 2416 \\
\hline United States & 2016 & 0.881 & 0.288 & 0.782 & 0.413 & 7296 \\
\hline Hungary & 1998 (MMD) & 0.877 & 0.294 & 0.794 & 0.405 & 1525 \\
\hline Australia & 2007 & 0.877 & 0.302 & 0.819 & 0.385 & 1873 \\
\hline Slovakia & 2010 & 0.875 & 0.307 & 0.827 & 0.378 & 1203 \\
\hline Republic of Korea & 2016 (SMD) & 0.874 & 0.3 & 0.819 & 0.385 & 2398 \\
\hline Greece & 2012 & 0.874 & 0.251 & 0.677 & 0.468 & 1029 \\
\hline United States & 2008 & 0.873 & 0.333 & 0.873 & 0.333 & 2102 \\
\hline New Zealand & 2014 (MMD) & 0.871 & 0.287 & 0.776 & 0.417 & 1224 \\
\hline Czech Republic & 2006 & 0.869 & 0.301 & 0.784 & 0.411 & 2002 \\
\hline Iceland & 2007 & 0.867 & 0.308 & 0.787 & 0.409 & 1595 \\
\hline Sweden & 1998 & 0.866 & 0.296 & 0.774 & 0.418 & 1157 \\
\hline Switzerland & 2003 & 0.866 & 0.309 & 0.811 & 0.392 & 1418 \\
\hline Romania & 2009 (Round 2) & 0.865 & 0.342 & 0.865 & 0.342 & 1403 \\
\hline Australia & 2013 & 0.864 & 0.302 & 0.785 & 0.411 & 3953 \\
\hline Austria & 2017 & 0.864 & 0.31 & 0.791 & 0.407 & 2406 \\
\hline Iceland & 2003 & 0.858 & 0.318 & 0.783 & 0.412 & 1446 \\
\hline Iceland & 1999 & 0.857 & 0.309 & 0.769 & 0.422 & 1631 \\
\hline Brazil & 2006 (Round 2) & 0.856 & 0.351 & 0.856 & 0.351 & 1000 \\
\hline
\end{tabular}




\begin{tabular}{|c|c|c|c|c|c|c|}
\hline Czech Republic & 2013 & 0.855 & 0.274 & 0.674 & 0.469 & 1653 \\
\hline Uruguay & 2009 (Round 2) & 0.855 & 0.352 & 0.855 & 0.352 & 968 \\
\hline Poland & 2005 & 0.855 & 0.298 & 0.695 & 0.461 & 240 \\
\hline Hungary & 1998 (SMD) & 0.855 & 0.312 & 0.762 & 0.426 & \\
\hline Chile & 2009 & 0.854 & 0.274 & 0.755 & 0.43 & \\
\hline Denmark & 2001 & 0.851 & 0.309 & 0.773 & 0.419 & \\
\hline United States & 1996 & 0.85 & 0.346 & 0.827 & 0.378 & \\
\hline Italy & 2018 (SMD) & 0.85 & 0.317 & 0.741 & 0.44 & \\
\hline Germany & 2013 (SMD) & 0.849 & 0.28 & 0.701 & 0.458 & \\
\hline Greece & 2009 & 0.849 & 0.31 & 0.727 & 0.446 & \\
\hline Argentina & 2015 (Round 1) & 0.849 & 0.297 & 0.725 & 0.447 & \\
\hline Taiwan & 2008 & 0.849 & 0.358 & 0.849 & 0.358 & \\
\hline Poland & 2001 & 0.848 & 0.302 & 0.698 & 0.459 & \\
\hline Croatia & 2007 & 0.846 & 0.33 & 0.771 & 0.42 & \\
\hline Denmark & 1998 & 0.846 & 0.315 & 0.764 & 0.425 & \\
\hline Great Britain & 1997 & 0.844 & 0.35 & 0.81 & 0.392 & \\
\hline Germany & 2013 (MMD) & 0.844 & 0.286 & 0.699 & 0.459 & \\
\hline Kenya & 2013 & 0.843 & 0.324 & 0.749 & 0.434 & \\
\hline Austria & 2013 & 0.843 & 0.294 & 0.693 & 0.462 & \\
\hline Estonia & 2011 & 0.841 & 0.34 & 0.784 & 0.412 & \\
\hline Romania & 2014 (Round 2) & 0.841 & 0.366 & 0.841 & 0.366 & \\
\hline Portugal & 2009 & 0.84 & 0.323 & 0.717 & 0.451 & \\
\hline Bulgaria & 2001 & 0.84 & 0.23 & 0.466 & 0.499 & \\
\hline Great Britain & 2005 & 0.837 & 0.355 & 0.806 & 0.396 & \\
\hline Albania & 2005 (MMD) & 0.836 & 0.332 & 0.719 & 0.45 & \\
\hline Poland & 1997 & 0.834 & 0.294 & 0.626 & 0.484 & 20 \\
\hline Sweden & 2002 & 0.832 & 0.329 & 0.745 & 0.436 & \\
\hline Ireland & 2011 & 0.832 & 0.327 & 0.659 & 0.474 & \\
\hline Chile & 2005 & 0.832 & 0.35 & 0.791 & 0.407 & \\
\hline Germany & 2002 (SMD) & 0.832 & 0.316 & 0.578 & 0.494 & 30 \\
\hline Peru & 2001 & 0.831 & 0.293 & 0.699 & 0.459 & 11 \\
\hline Bulgaria & 2014 & 0.831 & 0.317 & 0.651 & 0.477 & \\
\hline France & 2012 (Round 2) & 0.83 & 0.376 & 0.83 & 0.376 & 20 \\
\hline Denmark & 2007 & 0.83 & 0.323 & 0.729 & 0.444 & 14 \\
\hline Brazil & 2006 (Round 1) & 0.827 & 0.326 & 0.697 & 0.46 & 10 \\
\hline Canada & 2004 & 0.827 & 0.354 & 0.776 & 0.417 & 167 \\
\hline Norway & 2013 & 0.826 & 0.282 & 0.572 & 0.495 & 172 \\
\hline Germany & 1998 (SMD) & 0.826 & 0.333 & 0.676 & 0.468 & 20 \\
\hline Portugal & 2005 & 0.826 & 0.327 & 0.657 & 0.475 & 280 \\
\hline Sweden & 2014 & 0.825 & 0.324 & 0.712 & 0.453 & 83 \\
\hline Germany & 2005 (SMD) & 0.825 & 0.325 & 0.686 & 0.464 & 20 \\
\hline Netherlands & 1998 & 0.824 & 0.331 & 0.69 & 0.463 & 210 \\
\hline Portugal & 2015 & 0.823 & 0.219 & 0.424 & 0.495 & $14 \varsigma$ \\
\hline Finland & 2007 & 0.82 & 0.342 & 0.713 & 0.453 & $12 \varepsilon$ \\
\hline Switzerland & 2007 & 0.82 & 0.319 & 0.639 & 0.48 & \\
\hline Lithuania & 2016 (MMD) & 0.816 & 0.358 & 0.731 & 0.444 & 30 \\
\hline Ireland & 2016 & 0.816 & 0.333 & 0.704 & 0.457 & 20 \\
\hline Canada & 2008 & 0.814 & 0.353 & 0.733 & 0.442 & 44 \\
\hline Germany & 2002 (MMD) & 0.814 & 0.325 & 0.534 & 0.499 & \\
\hline Great Britain & 2015 & 0.814 & 0.339 & 0.705 & 0.456 & 15 \\
\hline
\end{tabular}




\begin{tabular}{|c|c|c|c|c|c|c|}
\hline New Zealand & 2014 (SMD) & 0.812 & 0.317 & 0.672 & 0.47 & 122 \\
\hline South Africa & 2014 & 0.81 & 0.308 & 0.583 & 0.493 & 130 \\
\hline Lithuania & 2016 (SMD) & 0.807 & 0.358 & 0.703 & 0.457 & 0 \\
\hline France & 2012 (Round 1) & 0.807 & 0.329 & 0.628 & 0.484 & $20^{-}$ \\
\hline Sweden & 2006 & 0.807 & 0.33 & 0.607 & 0.489 & \\
\hline Turkey & 2015 & 0.806 & 0.262 & 0.474 & 0.5 & \\
\hline Germany & 1998 (MMD) & 0.806 & 0.351 & 0.663 & 0.473 & \\
\hline Slovenia & 2011 & 0.803 & 0.345 & 0.597 & 0.491 & \\
\hline Finland & 2015 & 0.803 & 0.345 & 0.644 & 0.479 & \\
\hline Netherlands & 2006 & 0.802 & 0.328 & 0.635 & 0.482 & \\
\hline New Zealand & 2002 (MMD) & 0.802 & 0.34 & 0.661 & 0.474 & \\
\hline Finland & 2003 & 0.799 & 0.366 & 0.705 & 0.456 & \\
\hline Slovakia & 2016 & 0.797 & 0.341 & 0.659 & 0.475 & \\
\hline New Zealand & 2002 (SMD) & 0.797 & 0.348 & 0.675 & 0.469 & \\
\hline Japan & 1996 (MMD) & 0.796 & 0.382 & 0.759 & 0.428 & \\
\hline Poland & 2011 & 0.795 & 0.334 & 0.585 & 0.493 & \\
\hline Republic of Korea & 2008 (MMD) & 0.795 & 0.36 & 0.692 & 0.462 & 10 \\
\hline New Zealand & 2008 (MMD) & 0.794 & 0.335 & 0.579 & 0.494 & \\
\hline Serbia & 2012 (Round 1) & 0.792 & 0.345 & 0.654 & 0.476 & \\
\hline Finland & 2011 & 0.792 & 0.353 & 0.674 & 0.469 & 12 \\
\hline Spain & 1996 & 0.79 & 0.386 & 0.737 & 0.44 & 12 \\
\hline Czech Republic & 2010 & 0.789 & 0.357 & 0.662 & 0.473 & 18 \\
\hline Gerr & 2005 (MMD) & 0.787 & 0.35 & 0.64 & 0.48 & \\
\hline Serbia & 2012 (Round 2) & 0.787 & 0.41 & 0.787 & 0.41 & \\
\hline Latvia & 2014 & 0.786 & 0.345 & 0.645 & 0.479 & 10 \\
\hline Ireland & 2002 & 0.785 & 0.39 & 0.743 & 0.437 & 23 \\
\hline Austria & 2008 & 0.784 & 0.366 & 0.64 & 0.48 & \\
\hline lic of Korea & 2008 (SMD) & 0.782 & 0.359 & 0.653 & 0.476 & \\
\hline Israel & 1996 & 0.782 & 0.413 & 0.782 & 0.413 & 10 \\
\hline Mexico & 2012 & 0.779 & 0.365 & 0.687 & 0.464 & 24 \\
\hline Romania & 1996 & 0.779 & 0.398 & 0.713 & 0.452 & \\
\hline Germany & 2009 (SMD) & 0.778 & 0.377 & 0.666 & 0.472 & \\
\hline Switzerland & 2011 (MMD) & 0.777 & 0.356 & 0.656 & 0.475 & 43 \\
\hline Romania & 2004 (Round 1) & 0.777 & 0.397 & 0.716 & 0.451 & \\
\hline France & 2002 (Round 1) & 0.776 & 0.335 & 0.578 & 0.494 & \\
\hline Belgium & 1999 & 0.776 & 0.375 & 0.667 & 0.471 & \\
\hline Romania & 2009 (Round 1) & 0.776 & 0.334 & 0.491 & 0.5 & 14 \\
\hline Chile & 2017 (Round 2) & 0.775 & 0.418 & 0.775 & 0.418 & 40 \\
\hline Netherlands & 2002 & 0.772 & 0.355 & 0.619 & 0.486 & \\
\hline New Zealand & 2008 (SMD) & 0.772 & 0.345 & 0.544 & 0.498 & $11<$ \\
\hline Belgium & 2003 & 0.772 & 0.38 & 0.667 & 0.471 & 222 \\
\hline Peru & 2006 & 0.772 & 0.351 & 0.643 & 0.479 & 20 \\
\hline Greece & 2015 (January) & 0.769 & 0.348 & 0.531 & 0.499 & 10 \\
\hline Norway & 1997 & 0.767 & 0.363 & 0.614 & 0.487 & 205 \\
\hline Iceland & 2013 & 0.766 & 0.368 & 0.656 & 0.475 & 147 \\
\hline Japan & 1996 (SMD) & 0.765 & 0.405 & 0.734 & 0.442 & 132 \\
\hline New Zealand & 2011 (MMD) & 0.765 & 0.309 & 0.447 & 0.497 & 137 \\
\hline Romania & 2004 (Round 2) & 0.763 & 0.425 & 0.763 & 0.425 & 19 \\
\hline Romania & 2014 (Round 1) & 0.761 & 0.321 & 0.445 & 0.497 & 11 \\
\hline Israel & 2013 & 0.754 & 0.366 & 0.58 & 0.494 & $10^{\prime}$ \\
\hline
\end{tabular}


Continuous Consistent Voting

\begin{tabular}{|c|c|c|c|c|c|c|}
\hline Brazil & 2002 (Round 1) & 0.753 & 0.372 & 0.593 & 0.491 & 25 \\
\hline New Zealand & 1996 (MMD) & 0.752 & 0.377 & 0.635 & 0.481 & \\
\hline Norway & 2005 & 0.749 & 0.353 & 0.535 & 0.499 & \\
\hline Germany & 2009 (MMD) & 0.747 & 0.395 & 0.628 & 0.483 & \\
\hline New Zealand & 2011 (SMD) & 0.744 & 0.318 & 0.424 & 0.494 & \\
\hline Netherlands & 2010 & 0.743 & 0.383 & 0.621 & 0.485 & \\
\hline Slovenia & 2004 & 0.741 & 0.405 & 0.646 & 0.479 & \\
\hline Slovenia & 2008 & 0.741 & 0.389 & 0.49 & 0.5 & \\
\hline Brazil & 2010 (Round 1) & 0.736 & 0.393 & 0.622 & 0.485 & \\
\hline Chile & 1999 & 0.734 & 0.381 & 0.625 & 0.484 & \\
\hline Peru & 2011 & 0.733 & 0.395 & 0.623 & 0.485 & \\
\hline Slovenia & 1996 & 0.729 & 0.419 & 0.636 & 0.481 & \\
\hline New Zealand & 1996 (SMD) & 0.725 & 0.389 & 0.604 & 0.489 & \\
\hline Albania & 2005 (SMD) & 0.723 & 0.37 & 0.534 & 0.499 & \\
\hline Mexico & 2000 & 0.719 & 0.387 & 0.551 & 0.498 & \\
\hline Israel & 2006 & 0.718 & 0.41 & 0.594 & 0.491 & \\
\hline Latvia & 2011 & 0.706 & 0.343 & 0.386 & 0.487 & \\
\hline Greece & 2015 (September) & 0.704 & 0.376 & 0.463 & 0.499 & \\
\hline Canada & 1997 & 0.704 & 0.419 & 0.628 & 0.484 & \\
\hline Portugal & 2002 & 0.703 & 0.352 & 0.37 & 0.483 & \\
\hline Brazil & 2010 (Round 2) & 0.7 & 0.459 & 0.7 & 0.459 & \\
\hline Iceland & 2009 & 0.698 & 0.387 & 0.532 & 0.499 & \\
\hline Republic of Korea & 2012 (MMD) & 0.697 & 0.366 & 0.407 & 0.492 & \\
\hline Argentina & 2015 (Round 2) & 0.693 & 0.461 & 0.693 & 0.461 & \\
\hline Germany & 2017 (SMD) & 0.692 & 0.403 & 0.557 & 0.497 & \\
\hline Norway & 2001 & 0.691 & 0.378 & 0.381 & 0.486 & 20 \\
\hline Chile & 2017 (Round 1) & 0.688 & 0.368 & 0.357 & 0.479 & \\
\hline Brazil & 2002 (Round 2) & 0.685 & 0.465 & 0.685 & 0.465 & \\
\hline Germany & 2017 (MMD) & 0.68 & 0.409 & 0.549 & 0.498 & 40 \\
\hline Switzerland & 2011 (SMD) & 0.672 & 0.385 & 0.505 & 0.5 & 43 \\
\hline Latvia & 2010 & 0.669 & 0.371 & 0.406 & 0.491 & \\
\hline Ireland & 2007 & 0.666 & 0.44 & 0.424 & 0.494 & \\
\hline Republic of Korea & 2012 (SMD) & 0.666 & 0.377 & 0.384 & 0.487 & 10 \\
\hline Taiwan & 1996 & 0.611 & 0.484 & 0.603 & 0.49 & 120 \\
\hline France & 2002 (Round 2) & 0.569 & 0.496 & 0.569 & 0.496 & \\
\hline Belgium & 1999 & 0.568 & 0.441 & 0.354 & 0.478 & \\
\hline Philippines & 2010 & 0.557 & 0.439 & 0.34 & 0.474 & 12 \\
\hline Philippines & 2016 & 0.442 & 0.476 & 0.384 & 0.487 & \\
\hline
\end{tabular}

